\title{
IGUALDADE DE DIREITOS PARA MULHERES E HOMENS: UM TESTEMUNHO HISTÓRICO INSPIRADOR
}

EQUAL RIGHTS FOR WOMEN AND MEN: AN INSPIRING HISTORICAL TESTIMONY

Susana Antas Videira'

Universidade de Lisboa

\section{Resumo}

A igualdade, enquanto valor universal, assume uma plêiade de dimensões, sendo uma delas a igualdade entre homens e mulheres. Embora esta dimensão da igualdade constitua uma decorrência indeclinável do princípio universal plasmado na Declaração Universal dos Direitos do Homem, a verdade é que as sociedades contemporâneas ainda não a observam de forma plena e consolidada. Palavras-chaves

Igualdade. Homem. Mulher. Direito

\begin{abstract}
Equality, as a universal value, takes on a plethora of dimensions, one of which is equality between men and women. Although this dimension of equality is an indelible consequence of the universal principle of the Universal Declaration of Human Rights, the truth is that contemporary societies have not yet fully observed it.
\end{abstract}

Keywords

Equality. Men. Women. Rights

1 Professora da Faculdade de Direito da Universidade de Lisboa Investigadora do Centro de Investigação em Teoria e História do Direito da Universidade de Lisboa (THD-ULisboa) 


\section{Revista da Faculdade Mineira de Direito $\mid$ V.20 N.40|2}

Já antes escrevemos que as ideias têm a força de governar o mundo e exercem um poder decisivo na História já que, na generalidade das situações, expressam aspirações humanas e dependem, para a sua cabal realização, do voluntarismo do homem² ${ }^{2}$.

É, esse, precisamente, o caso da ideia de igualdade, peça axial para que se logre alcançar, na medida do humanamente possível, uma condição de felicidade generalizada.

A igualdade, enquanto valor universal, assume uma plêiade de dimensões, sendo uma delas a igualdade entre homens e mulheres.

Embora esta dimensão da igualdade constitua uma decorrência indeclinável do princípio universal plasmado na Declaração Universal dos Direitos do Homem, a verdade é que as sociedades contemporâneas ainda não a observam de forma plena e consolidada.

Muito ao invés, verifica-se um hiato que persiste e que resiste, ainda que os contornos sejam hoje menos nítidos ou as cores mais esbatidas em resultado da intervenção, da meditação e da sensibilização para este fenómeno.

Por outras palavras, as sociedades assumem-se cada vez mais igualitárias e reconhecedoras da eminente dignidade da pessoa humana, sem olhar a género como fator discriminatório.

Todavia, a mera observação também revela que não existe, ainda, neste contexto, um padrão universal, nem se trata de um valor absolutamente conquistado.

Permanecem, ao invés, sinais perturbadores de fragilidade para os quais cumpre olhar atentamente, impondo-se refletir criticamente sobre os fatores que explicam a persistência da discriminação fundada no género.

2 Cfr. Susana Antas Videira, «O diálogo histórico entre a afirmação da liberdade e a garantia da igualdade. Algumas considerações», Duc in Altum, Cadernos de Direito, Faculdade de Damas, v. 9, n. ${ }^{\text {o }}$ 18, 2017, p. 17. 


\section{Revista da Faculdade Mineira de Direito $\mid$ V.20 N.40 $\mid 3$}

A desigualdade verifica-se em diferentes áreas e com expressões distintas.

No mercado de trabalho as situações de desigualdade variam em todos os países e regiões do mundo e de forma muito diversa.

$\mathrm{Na}$ Europa, a disparidade salarial entre sexos nos trabalhadores por conta de outrem, em 2015, era de $16,3 \%$, variando entre os $26,9 \%$ na Estónia e os 5,5\% no Luxemburgo. Portugal situava-se nos $17,8 \%$.

Estes dados ${ }^{3}$ revelam que a remuneração média dos homens e a das mulheres nos vários setores da economia ainda apresenta uma fragmentação expressiva. Segundo a mesma fonte, a disparidade salarial tem vindo a aumentar nos últimos anos em Portugal. Em 2007, a divergência situava-se nos $8,5 \%$, aumentando quase $10 \%$ em menos de 10 anos. A discriminação salarial, embora seja ilegal, continua a ser um importante fator de discriminação entre géneros. Em sentido diverso, verifica-se que, no âmbito da Administração Pública, Portugal apresenta um quadro de dirigentes superiores da administração central maioritariamente do sexo feminino. Em 2016, de acordo com o Instituto Nacional de Estatística (INE), 5810 dirigentes superiores eram mulheres e 5505 homens.

Já no contexto do setor privado, o cenário é diferente.

Em abril de 2016, a presença de mulheres nos conselhos de administração das empresas do PSI 20 era de 14\% contra 86\% de homens. $\mathrm{Na}$ União Europeia, a média era, no mesmo período, de $23 \%$ para as mulheres e de $77 \%$ para os homens ${ }^{4}$.

Relativamente à taxa de desemprego, verifica-se que, em 2016, em Portugal, esta foi igual para homens e mulheres $(11,2 \%)$.

Em sede de parentalidade, ressalta uma evolução significativa da proporção de homens que partilharam com as mulheres a licença

\footnotetext{
${ }^{3}$ Fonte: Pordata http://www.pordata.pt/

${ }^{4}$ Fonte: EIGE http://eige.europa.eu/gender-statistics/dgs/browse/wmidm
} 


\section{Revista da Faculdade Mineira de Direito $\mid$ V.20 N.40 $\mid 4$}

inicial de 120/150 dias. Contudo, relativamente ao número de crianças nascidas, as mulheres continuam a apresentar a maior percentagem de licenças parentais. Em cada 100 crianças que nasceram em 2015, houve $85,4 \%$ de mulheres que gozaram a licença de parentalidade e $27,5 \%$ de homens partilharam essa licença ${ }^{5}$.

Entre os jovens que concluem o ensino superior, as mulheres, de acordo com o INE, estão em maioria em todas as áreas da educação, com exceção da Engenharia, das Indústrias Transformadoras e da Construção. Destaca-se ainda a baixa participação das mulheres nas Tecnologias de Informação e Comunicação.

$\mathrm{Na}$ perspetiva da violência, as mulheres continuam a integrar um grupo alvo expressivo. Segundo a Organização Mundial da Saúde, a violência contra as mulheres, particularmente a violência nas relações de intimidade e a violência sexual, constituem, nos dias de hoje um problema de saúde pública e uma grave violação dos direitos das mulheres. Esta organização estima, numa perspetiva global, que cerca de 1 em cada 3 mulheres já sofreram violência física ou psicológica nas relações de intimidade ou foram vítimas de violência sexual na sua vida. Cerca de 38\% dos homicídios em que as vítimas são do sexo feminino resultam de violência no contexto das relações de intimidade e os agressores são do sexo masculino.

No caso do tráfico de seres humanos, globalmente encarado, em todas as suas dimensões, as mulheres também surgem como as vítimas mais expressivas: cerca de três quartos de todo o tráfico e cerca de 95\% no caso do tráfico para fins de exploração sexual.

Acresce que as mulheres continuam a ter um risco de pobreza mais elevado do que os homens e, em 2015, o valor dessa taxa era, em

5 Comissão para a Igualdade no Trabalho e no Emprego (CITE) http://cite.gov.pt/ e PORDATA http://www.pordata.pt/ 


\section{Revista da Faculdade Mineira de Direito $\mid$ V.20 N.40 | 5}

Portugal, superior ao registado na década anterior, segundo divulgação do INE. Este padrão é, no entanto, idêntico à escala mundial.

A igualdade entre homens e mulheres, que o século XXI persiste em desconsiderar, surge, nítida, nas ideias inspiradoras de Marie Jean Antoine Nicolas de Caritat, marquês de Condorcet, com quem o naturalismo iluminista francês conhece o seu ponto alto.

Condorcet nasce em 17 de Setembro de 1743, no seio de uma família aristocrática, e morre, de forma não inteiramente esclarecida, no final de Março de 1794.

Cedo se inclinou para as matemáticas, com notável sucesso, o que lhe permitiu conquistar a amizade de D'Alembert.

Tinha apenas vinte anos quando experimenta a sua "revolução moral" e se aproxima dos "philosophes".

O seu encontro com a "nova moral", que nunca descreveu com rigor, leva-o a combater os preconceitos estabelecidos contra alguns sectores marginalizados ou perseguidos, como as mulheres, os homossexuais, as mães solteiras, os ateus, os escravos negros das colónias.

Em 1769, com apenas vinte e cinco anos, é eleito membro da Academia das Ciências. A sua proximidade dos "savants" como D' Alembert, Condillac, Diderot, Voltaire, Helvécio e Turgot expressa-se na colaboração na Enciclopédia.

Entre 1776 e 1789, o pensamento condorcetiano é marcado por cinco importantes acontecimentos: a revolução americana, o ensaio francês das assembleias provinciais, a bancarrota e a desordem financeira, o programa de governo apresentado pelo rei em 1788 e a convocatória dos estados gerais, já no ano de 1789 .

Acreditando que era possível reformar profundamente a sociedade, interessa-se pelas questões económicas, numa perspectiva fisiocrata. Tal interesse leva-o a publicar um resumo da obra maior de Adam Smith, A Riqueza das Nações. A sua obra maior 


\section{Revista da Faculdade Mineira de Direito $\mid$ V.20 N.40 6}

é, porém, o Esquisse d'un tableau historique des progrès de l'esprit human, datado de $1794^{6}$.

O cepticismo perante os dogmas e a confiança na capacidade transformadora do homem fazem daquele que D'Alembert definiria como um vulcão coberto de neve um pensador singular. A sua actividade intelectual é prodigiosa, desde logo pela profusão de temas que abraça e pelas preocupações sociais que deixa transparecer. De salientar as suas reflexões sobre a humanidade, o livre-pensamento, a tolerância, a igualdade, a justiça e a liberdade.

Interessa-nos, neste contexto, reter que a sua confiança nas potencialidades do homem é infinita. Escutemo-lo: Intento mostrar através de que escalões o que hoje nos parece uma esperança quimérica passará, sucessivamente, a ser possivel e inclusivamente fácil; há que mostrar porque é que, apesar do sucesso efémero e do apoio que recebem os governos corruptos, somente a verdade deve obter um triunfo duradouro; e há, ainda, que revelar mediante que laços a natureza uniu indissociavelmente os progressos das luzes e os da virtude, o respeito pelos direitos naturais e pela felicidade. (...) A partir do momento em que esta revolução alcance toda a classe dos homens ilustrados, não se encontrarão entre eles mais do que amigos da humanidade, ocupados, de comum acordo, em acelerar o progresso e a felicidade . $^{2}$

Não obstante, o significado de Condorcet não está tanto na originalidade da sua construção política, mas antes no facto de apresentar, com as suas ideias, o essencial do pensamento francês do seu século, dando-lhe a necessária, e nem sempre antes conseguida, coerência. Intuindo isso mesmo, escreve: a filosofia já não tem nada que adivinhar, já não tem hipotéticas combinações a faz̧er; não

\footnotetext{
${ }^{6}$ Nas citações deste escrito recorremos à tradução castelhana Bosquejo de un cuadro histórico de los progresos del espíritu bumano, introdução e tradução revistas por Antonio Torres del Moral, Clásicos Políticos, Centro de Estudios Políticos y Constitucionales, Madrid, 2004. Não deixámos, porém, de a comparar com a edição francesa de 1790, Vrin, Paris, com apresentação de O. H. Prior.

${ }^{7}$ Condorcet, Bosquejo de un cuadro bistórico, cit., p. 9.
} 


\section{Revista da Faculdade Mineira de Direito $\mid$ V.20 N.40|7}

existe nada mais do que reunir e ordenar os factos e revelar as verdades úteis que nascem do seu encadeamento e do seu conjunto ${ }^{8}$.

Atentos os contornos do presente artigo, não importa traçar o itinerário seguido por Condorcet para chegar à sua concepção de Estado e de poder político. Por consequência, silenciamos as ideias que levam os seus intérpretes a ver nele um teórico do direito constitucional: o desenho que faz dos direitos naturais, a sua concepção de poder político como relativo e condicionado, as características que atribui à tirania e ao despotismo, a sua síntese das formas de governo e da divisão de poderes, o papel que reserva aos partidos políticos constituem tópicos dos quais não nos ocupamos. Não atentamos, ainda, na marca de Condorcet no nascimento da expressão democracia representativa?. Não desenvolvemos, tão pouco, a ideia de que, com Condorcet, o método da ciência social passa a assentar na razão, no cálculo matemático e na experiência. Calamos, de resto, o seu contributo para o progresso da Economia Política, como ciência, a crítica que lhe merece o mercantilismo e o proibicionismo e a defesa, em conformidade, da fisiocracia, bem como os seus ensinamentos em matéria tributária e financeira, área para a qual é dotado de uma competência excepcional $^{10}$.

Cuidaremos, em alternativa, do seu contributo para a afirmação de direitos iguais para ambos os sexos.

${ }^{8}$ Idem, ibidem.

${ }^{9}$ Foi defendido que Condorcet é o primeiro autor a utilizar a expressão em referência na $I V$ carta que escreve a um burguês de New-Haven, texto datado de 1787, onde se lê, a propósito das causas do desaparecimento das repúblicas antigas: "é possível concluir (...) que pereceram porque não conheciam os meios de articular uma democracia representativa, na qual existem a paz e a igualdade". Condorcet, Cartas de un burgués de New-Haven, XII, 121, apud António Torres del Moral, «Estudio Preliminar» a Condorcet, Bosquejo de un cuadro bistórico de los progresos del espiritu humano, cit. p. LX.

10 Sobre estas temáticas v. Franck Alengry, Condorcet. Guide de la Révolution Française, Slatkine Reprints, Genebra, 1971, sobretudo pp. 361 a 683. 


\section{Revista da Faculdade Mineira de Direito $\mid$ V.20 N.40|8}

Antes, porém, um brevíssimo enquadramento.

Como tantos, Condorcet participa da doutrina pactista que os séculos XVII e XVIII opõem à fundamentação divina da sociedade e comunga da ideia de que o facto social não está dependente de Deus, nem da vontade do homem, nem dos acasos da sorte ou das determinações da Natureza. Decorre, antes, de um acto fundacional reflexivo, o pacto social ${ }^{11}$. Porque os homens se constituem em sociedade para seu benefício e não em seu detrimento, o primeiro fim a atingir é o gozo pacífico e completo dos seus direitos. A manutenção dos verdadeiros direitos do homem escreve - é o único objectivo da reunião em sociedade política, pelo que a arte social devia consistir em assegurar a conservação desses direitos na mais completa igualdade e com a maior amplitude ${ }^{12}$. Precisando esta ideia, Condorcet traça, com brevidade e justeza, os principais fins da arte social, que se resumem a estender a todos o gozo dos direitos comuns que por natureza lhe correspondem ${ }^{13}$. E esses direitos são a segurança, a liberdade, o progresso e a igualdade ${ }^{14}$. Para o autor, todos os

11 A Condorcet não interessa discutir o estado pré-social, mas antes a possibilidade de uma posterior ordenação distinta mediante um pacto racional. Cfr. Condorcet, Bosquejo de un cuadro histórico, cit., «Primeira Época (os homens reúnem-se em população)», pp. 13 a 16.

12 Condorcet, Bosquejo de un cuadro bistórico, cit., «Nona Época (Desde Descartes até à formação da República francesa)» p. 116.

13 Condorcet, Bosquejo de un cuadro histórico, cit., «Décima Época (os progressos futuros do espírito humano)» p. 167.

14 Condorcet, Bosquejo de un cuadro histórico, cit., «Décima Época (os progressos futuros do espírito humano)», p. 157. Nitidamente influenciado pelas ideias de Thomas Paine e pela praxis norte-americana, apresenta, como direitos naturais do homem, a segurança e a liberdade pessoais; a segurança e a liberdade dos seus bens; a igualdade. Cfr. Condorcet, «Declaration des droits», in Oeuvres, publicadas por A. Condorcet O'Connor e M. F. Arago, (em 12 volumes), Paris, 1847-49, t. XII, p. 253. 


\section{Revista da Faculdade Mineira de Direito $\mid$ V.20 N.40|9}

demais fins a prosseguir ${ }^{15}$, como a justiça, a propriedade e a garantia social, são redutíveis a estes ${ }^{16}$.

Central é, para nós, o conceito condorcetiano de igualdade, o qual, todavia, não é fácil de reconstruir.

Condorcet surpreende-nos, a este nível, com uma análise que até então não conhecemos formulada com tanta precisão.

A generalidade dos apoios doutrinários do liberalismo insiste na liberdade, em detrimento da igualdade, que praticamente reduz a igualdade perante a lei. É, por isso, admirável que o autor se entregue a densificar o conceito de igualdade, a que faz corresponder o carácter de absoluto incondicionado que atribuía aos direitos naturais ${ }^{17}$. Com efeito, o direito natural de cada um não pode ser, estritamente, absoluto, pois tem como limite o direito natural do outro.

Também a igualdade não pode ser vista como um valor absoluto. Mas, enquanto conceito relacional, a igualdade deve ser postulada, instaurada e defendida absolutamente. E não se trata de uma asserção puramente teorética, já que Condorcet lhe atribui o significado político mais exigente: a afirmação da igualdade constitui para os poderes públicos uma obrigação positiva ${ }^{18}$.

Ademais, da igualdade derivam e à igualdade retornam todos os direitos naturais, como a liberdade e a segurança. Numa palavra, sem igualdade não existe liberdade nem, tão pouco, paz e felicidade ${ }^{19}$.

\footnotetext{
15 Para utilizarmos terminologia do autor. Cfr., v.g., p. 116 do seu Bosquejo de un cuadro histórico, cit.

16 Condorcet, Bosquejo de un cuadro bistórico, cit., sobretudo, p. 157. Também, «Declaration...», cit., XII, p. 417.

17 Idem, p. 116.

18 Idem, ibidem.

19 Idem, p. 158.
} 


\section{Revista da Faculdade Mineira de Direito $\mid$ V.20 N.40|10}

Se Condorcet elege a igualdade como fulcro da sua filosofia constitucional, não deixa, porém, de colocar em relevo as intimas vinculação entre este conceito e a liberdade, de tal forma que a igualdade surge não apenas como condição de liberdade, mas como seu sinónimo. Condorcet di-lo expressamente: Não esqueçamos que a igualdade de direitos e a liberdade são sinónimos ${ }^{20}$.

Por decorrência, a insistência de manter a liberdade sob o manto de condições naturalmente desiguais é um sofisma, no plano das ideias, porque, em sociedade, toda a desigualdade contrária à natureza é uma ofensa aos direitos da bumanidade ${ }^{21}$ e um insulto à liberdade que se pretende afirmar.

$\mathrm{O}$ essencial das suas ideias acerca da igualdade parte de uma interrogação: a diferença de luz̧es, de meios e de riquezas observada, até à data, em todo os povos civilizados, entre as diversas classes que os compõem; desigualdade essa que os primeiros progressos societários aumentaram é devida à civilização em si mesmo ou às imperfeições da arte social? ${ }^{22}$

A superação da dúvida exige uma precisão de natureza terminológica. Aceitando os ensinamentos de Rousseau ${ }^{23}$, o filósofo geómetra distingue a desigualdade natural, que não colide

${ }^{20}$ Cfr. Condorcet, Ensayo sobre las Asambleas Provinciales, XIV, 415.

${ }^{21}$ Condorcet, Bosquejo de un cuadro histórico, cit., p. 162.

22 Idem, p. 158.

$23 \mathrm{O}$ filósofo de Genebra arranca a Condorcet as seguintes palavras, de sincero elogio: "nada se deve atrever a dividir os homens em dois grupos diferentes, um destinado a governar e o outro a obedecer; um a mentir e o outro a ser enganado; há que reconhecer que todos têm igual direito a instruir-se acerca dos seus interesses, a conhecer todas as verdades; nenhum dos poderes estabelecidos pelos homens tem direito a ocultar-lhes alguma. Estes princípios que o generoso Sydney pagou com o seu sangue, a que Locke uniu a autoridade do seu nome, foram desenvolvidos depois por Rousseau com mais precisão, amplitude e força e a Rousseau cabe a glória de os ter colocado entre essas verdades que não podem ser combatidas nem esquecidas". Condorcet, Bosquejo de un cuadro histórico, cit., «Nona Época (Desde Descartes até à formação da República francesa)», p. 118. 


\section{Revista da Faculdade Mineira de Direito $\mid$ V.20 N.40|11}

com o respectivo direito, da desigualdade institucional, criação arbitrária das instituições sociais, que fere a igualdade de direitos ${ }^{24}$.

Condorcet inova, porém, quando densifica esta distinção.

A observação histórica das sociedades revela a existência de um hiato profundo entre os direitos que a lei reconhece aos cidadãos e os que estes realmente gozam; entre a igualdade estabelecida pelas instituições políticas e a que existe entre os indivíduos ${ }^{25}$. Numa terminologia que não é a do século em que escreve, Condorcet opõe, com precisão, a igualdade formal à igualdade real.

Progredindo no seu raciocínio, adianta Condorcet três razões fundamentais para a divergência excessiva, que, na sua opinião, constitui uma das principais causas de destruição da liberdade nas antigas repúblicas, das tormentas que as sacudiram e da debilidade que as entregou ao jugo de tiranos estrangeiros ${ }^{26}$. São elas: a desigualdade de riqueza entre os que pouco ou nada têm e os detentores das fortunas; a desigualdade entre os proprietários de bens perenes e, portanto, transmissíveis mortis causa e os que não detém mais do que aquilo que lhes proporciona o seu trabalho e a desigualdade de instrução ${ }^{27}$.

Interessa-nos esta última dimensão ${ }^{28}$, para auscultarmos $\mathrm{O}$ significado de Condorcet para o tópico objecto do presente artigo: a igualdade de direitos entre mulheres e homens.

Mas antes deixemos a seguinte consideração, a título de enquadramento: não tem razão Hippolyte Taine quando considera

24 Cfr. Condorcet, Bosquejo de un cuadro histórico, cit., «Décima Época (os progressos futuros do espírito humano)» pp. 158 e 162.

25 Idem, p. 162.

26 Idem, ibidem.

27 Idem, pp. 162 a 164.

28 Para mais desenvolvimentos V. o nosso Liberalismo e Questão Social em Portugal no século XIX. Contributo para a História dos Direitos Sociais, com prefácio do Prof. Doutor António Pedro Barbas Homem, Lisboa, AAFDL, 2016, pp. 197 e ss. 


\section{Revista da Faculdade Mineira de Direito | V.20 N.40|12}

Condorcet um nivelador por sistema ${ }^{29}$. O igualitarismo, na sua visão de cidade ideal $^{30}$, não é o objectivo a alcançar. A desigualdade natural não pode desaparecer, deve apenas ser atenuada, porque, nas palavras do autor, seria absurdo e perigoso querer destruir o que é necessário ${ }^{31}$. O que Condorcet não aceita são as desigualdades institucionais, criação arbitrária das instituições sociais ${ }^{32}$. No fundo, na versão terrena da Cidade de Deus ${ }^{33}$, que idealiza no derradeiro capítulo do seu Esquisse, aspira Condorcet a uma igualdade de direito e não de facto.

Por consequência, a teoria da perfectibilidade humana, gizada pelo Iluminismo e recuperada pelo Liberalismo, entendida em termos de processo de racionalização, surge nítida em Condorcet de acordo com o modelo da ciência moderna.

Na sua construção doutrinária, o progresso da humanidade aparece associado ao crescimento económico, ao desenvolvimento da técnica, à garantia das liberdades civis, à anulação das desigualdades sociais e à supressão da miséria.

Existe, ademais, nele uma concepção linear do progresso civilizacional - que aparece, depois, também em Karl Marx, Comte, H. Herbert Spencer ou Charles Darwin, potenciado pelo progresso do espírito humano. Ao conhecimento atribui a modernização tecnológica, o crescimento económico, a melhoria das condições de vida das populações e a, consequente, eliminação

${ }^{29}$ Hippolyte Taine, Les origines de la France contemporaine, 5 tomos, Les Éditions Robert Laffont, collection Bouquins, 1986, t. III, p. 111.

30 Tal como a concebe na Décima Época do seu Esquisse. Cfr. Bosquejo de un cuadro histórico, cit., «Décima Época (os progressos futuros do espírito humano)»pp. 157 a 184 da ed. cit.

31 Condorcet, Bosquejo de un cuadro histórico, cit., «Décima Época (os progressos futuros do espírito humano)» p. 163.

32 Idem, ibidem.

${ }^{33}$ Nas palavras de António Truyol y Serra, Filosofia do Direito e do Estado, 2, Inst. de Novas Profissões, 1990, p. 342. 


\section{Revista da Faculdade Mineira de Direito $\mid$ V.20 N.40|13}

da penúria. Como notou Habermas, Condorcet crê na vida eterna antes da morte $e^{34}$.

É chegado agora o momento de apresentar o essencial do seu pensamento sobre o tema que elegemos para tutelar este artigo.

Seguindo um método preferencialmente dedutivo e usando de grande força lógica, Condorcet defende direitos iguais para ambos os sexos: entre os progressos do espirito bumano mais importantes para a felicidade geral, devemos contar a total destruição dos preconceitos que estabeleceram entre os dois sexos uma desigualdade de direitos, funesta, inclusivamente, para o sexo que se pretende favorecer ${ }^{35}$.

Com inquestionável rigor lógico, retira da própria definição de direitos naturais a conclusão de que a desigualdade de direitos entre homens e mulheres é inútil e não tem outra origem que não o abuso da força $a^{36}$.

No seu famoso opúsculo Sur l'admission des femmes au droit de cité escreve, a este propósito, que os direitos dos homens resultam unicamente do facto de constituírem seres sensíveis, capazes de adquirirem ideias morais e de combinarem essas ideias ${ }^{37}$.

Nas suas palavras, tão sugestivas, as mulheres que têm, então, as mesmas qualidades, têm necessariamente os mesmos direitos. Ou nenhum indivíduo da espécie humana tem verdadeiros direitos, ou todos têm os mesmos; e aquele que vota contra os direitos do outro, seja qual for a sua religião, cor ou sexo, desde logo abjurou o seu próprio. E, prossegue: seria difícil provar que as mulheres são incapazes de exercer os direitos de cidadania. Embora possam tornar-se mães de família e expostas a outras indisposições passageiras, por que não podem exercer direitos que nunca foram propostos para privar as pessoas que periodicamente sofrem de gota, bronquite, etc.? Admitindo, por enquanto, que

34 Jürgen Habermas, Théorie de l'Agir Communicationnel, tomo I, Paris, Fayard, 1987, p. 164.

35 Cfr. Condorcet, Bosquejo de un cuadro bistórico, cit., «Décima Época (os progressos futuros do espírito humano)» p. 175.

36 Idem, ibidem.

${ }^{37}$ Condorcet, Sur l'admission des femmes au droit de cité, Paris, 1790. 


\section{Revista da Faculdade Mineira de Direito | V.20 N.40|14}

existe nos homens uma superioridade de espirito, que não é o resultado necessário de uma diferença de educação (que não é de modo algum provada, mas que deveria ser, permitir que as mulheres sejam privadas de um direito natural sem injustica). Essa inferioridade só pode consistir em dois pontos. Diz-se que nenhuma mulher fez qualquer descoberta importante na ciência, ou deu provas da posse do gênio em artes, literatura, etc. Mas, por outro lado, não se tem intenção de afirmar que os direitos de cidadania sejam concedidos apenas aos homens de gênio. Acrescenta-se que nenhuma mulher tem o mesmo grau de conhecimento, o mesmo poder de raciocínio, que certos homens. Mas, o que resulta disso? Só que, com exceção de um número limitado de bomens excepcionalmente esclarecidos, a igualdade é absoluta entre as mulheres e o restante dos homens; Que esta pequena classe à parte, inferioridade e superioridade são igualmente divididos entre os dois sexos. Mas, uma vez que seria completamente absurdo restringir a essa classe superior os direitos de cidadania e o poder de ser confiado a funções públicas, porque razão as mulheres deveriam ser excluidas mais do que aqueles homens que são inferiores a um grande número de mulheres? ${ }^{38}$

Por consequência, negar à mulher, que partilha essa natureza, o direito de cidadania constitui uma fonte demasiado fecunda de injustiças, de crueldades e de crimes ao manter uma oposição perigosa entre a inclinação natural mais viva - e, por isso, mais dificil de reprimir - e os deveres do homem ou os interesses da sociedade ${ }^{39}$.

Nestes termos, carece de sentido a afirmação, tantas vezes repetida, de que a atribuição à mulher de direitos políticos contribui para a afastar da família. Se assim é, observa Condorcet, há que excluir da titularidade desses direitos todos quantos prosseguem uma actividade e têm uma ocupação útil, reservando-os, apenas, a uma aristocracia endinheirada e ociosa ${ }^{40}$.

38 Condorcet, Sur l'admission des femmes au droit de cité, 1790, p. 5.

39 Condorcet, Bosquejo de un cuadro histórico, cit., «Décima Época (os progressos futuros do espírito humano)» p. 176.

${ }^{40}$ Condorcet, Sur l'admission des femmes au droit de cité, Paris, 1790, p. 6. 


\section{Revista da Faculdade Mineira de Direito $\mid$ V.20 N.40|15}

Por outro lado, é absolutamente verdadeiro que as mulheres não são governadas pela razão (e pela experiência) dos homens, porquanto, afirma o ilustrado Marquês, são governadas pela sua própria razão e experiência ${ }^{41}$.

Justificada a não discriminação, e, por consequência, o direito de voto às mulheres, o olhar do autor volta-se para outro tema, que também reclama detalhadamente a sua atenção: a necessidade de instrução comum para homens e mulheres.

Como ponto de partida temos a ideia de que a instrução pública é um dever da sociedade para com os seus cidadãos ${ }^{42}$.

O acento tónico, a este nível, não deve estar na quantidade de conhecimentos que se transmitem, mas na orientação da instrução, que constitui uma obrigação positiva do Estado. Escreve, a este propósito, Condorcet: mediante afortunada orientação, quanto aos conbecimentos em si mesmos e quanto aos métodos de os transmitir, pode ser instruida a massa inteira de um povo acerca de tudo o que cada homem tem necessidade de saber para a economia doméstica, para a administração dos seus assuntos, para o livre progresso da sua indústria e das suas faculdades, para conbecer os seus direitos, defendê-los e exercê-los, para instruir-se acerca dos seus deveres e para bem os cumprir, para julgar os seus actos e os albeios, segundo as suas próprias luzes e não ser estranho a nenhum dos sentimentos elevados ou delicados que honram a natureza bumana, para não depender cegamente daqueles a quem o homem está obrigado a confiar o cuidado dos seus assuntos e o exercicio dos seus direitos, para estar em condições de os eleger e vigiar, para não ser a vítima dos erros populares que atormentam a vida com supersticiosos terrores e quiméricas esperanças, para se defender contra os preconceitos apenas com as forças da razãa $0^{43}$.

41 Idem, ibidem, p. 7.

42 Condorcet, Cinq mémoires sur l'instruction publique (1791), Apresentação, Notas, Bibliografia e Cronologia por Charles Coutel e Catherine Kintzler, GarnierFlammarion, Paris, 1994, «Primeira Memória», p. 14.

43 Condorcet, Bosquejo de un cuadro histórico, cit., «Décima Época (os progressos futuros do espírito humano)» p. 165. 


\section{Revista da Faculdade Mineira de Direito $\mid$ V.20 N.40|16}

Como matriz temos que a instrução deve ser orientada no sentido de excluir toda a dependência, forçada ou voluntária, do ignorante relativamente ao instruído ${ }^{44}$.

Para Condorcet, e é este outro motivo de interesse do seu pensamento, o círculo da desigualdade só se combate traçando o círculo de sinal contrário. Vale a pena devolver-lhe a palavra: as diversas causas da desigualdade não actuam de uma maneira isolada; antes se unem, se interpenetram, se sustentam e da combinação dos seus efeitos resulta uma acção mais forte, mais segura e mais constante. Se a instrução é igual para todos, dela nasce uma maior igualdade no exercicio profissional e, por conseguinte, nas fortunas e a igualdade de fortunas gera, necessariamente, a possibilidade de instrução $0^{45}$.

A instrução, portanto, deve ser comum a homens e a mulheres. Ainda que reconheça que as mulheres se sentem mais inclinadas para o cuidado doméstico, não aceita que, partindo dessa observação de facto, se lhes negue o direito a uma instrução igual. Por vários motivos, que o autor não deixa de expressar. Em primeiro lugar, uma mulher instruída cuida melhor da educação dos seus filhos ${ }^{46}$. E a este propósito importa notar que o ideal pedagógico condorcetiano assenta na educação partilhada entre o pai e a mãe, prática pouco mais do que ignorada no seu tempo e que revela, uma vez mais, o traço progressivo do seu pensamento ${ }^{47}$. Em segundo lugar, porque a falta de instrução da mulher introduz no meio familiar um desequilíbrio acentuado entre marido e mulher, irmão e irmã, mãe e filho. Ora, a desigualdade de instrução entre os membros de uma mesma família compromete a felicidade

\footnotetext{
44 Idem, ibidem.

45 Idem, p. 166.

46 Condorcet, Cinq mémoires sur l'instruction publique, «Primeira Memória», cit., S VI (“É necessário que as mulheres partilhem a educação dada aos homens"), p. 46. ${ }^{47}$ Idem, p. 48.
} 


\section{Revista da Faculdade Mineira de Direito | V.20 N.40|17}

e a paz no seu seio, por poder conduzir ao desprezo de uns pelos outros $^{48}$.

Só a instrução potencia o desaparecimento dos preconceitos que criaram entre os sexos uma artificial desigualdade de direitos e, por consequência, a plena incorporação política, social e cultural da mulher.

Por consequência, e em síntese, a igualdade é o conceito integrador e unificador do pensamento político de Condorcet $^{49}$, que o leva a afirmar com veemência direitos iguais para ambos os sexos.

Mas, para além da igualdade, há outro princípio que está presente em toda a construção condorcetiana: o progresso. Acompanhando o ideal reformista da Ilustração que se identifica com a busca da perfectibilidade humana, aquele que já foi considerado o último ilustrado ${ }^{50}$ dedica, precisamente, ao progresso o seu Esquisse, obra que não conseguiu completar ${ }^{51}$.

Mas, a ideologia ilustrada do progresso carecia da ciência histórica. Essa necessidade é sentida pelo autor quando, nas notas introdutórias, apresenta a metodologia que se propõe seguir ${ }^{52}$.

Condorcet concebe a História da Civilização dividida em nove épocas, às quais adita uma última em que, com afastamento dos dados históricos, prediz o futuro num extraordinário exercício intelectual sobre os progressos do espirito humano. Com a entrada na plenitude das luzes, potenciada pela revolução Francesa - a qual

\footnotetext{
48 Idem, p. 47.

49 Como observa Franck Alengry, Condorcet..., cit., pp. 400 e 680.

${ }^{50}$ Nas palavras de António Torres del Moral, «Estudio Preliminar», a Bosquejo de um cuadro histórico de los progresos del espírito bumano, cit., p. XV.

51 Como o próprio título indicia o Esquisse pretende ser a introdução de uma obra de notáveis dimensões. Só as notas manuscritas que se conservam quadruplicam a sua extensão.

52 Condorcet, «Introdução» a Bosquejo de um cuadro histórico de los progressos del espírito bumano, cit., p. 4.
} 


\section{Revista da Faculdade Mineira de Direito $\mid$ V.20 N.40|18}

encerra a nona época, a última verdadeiramente histórica - o homem caminha para a perfeição e para a felicidade universal ${ }^{53}$. A leitura atenta das páginas que dedica à caracterização da Décima Época leva-nos a concluir que o inspirado geómetra acreditava que a sua sociedade exemplar era real.

O progresso do espírito e da razão, da ciência e da filosofia, dos direitos do homem e, em particular, da igualdade, do pacifismo e do livre pensamento triunfariam sobre a superstição, o preconceito, a ignorância e a exploração do ser humano pelo ser humano. No fundo, a justiça sobre o despotismo. Apenas resta saber orientá-lo. Tal missão é entregue, por Condorcet, a um sistema de leis, de segurança social e de instrução obrigatória e gratuita para ambos os sexos digno do século que alcançou, afinal, o brilho das luzes.

Saibamos nós honrar a integridade e a coerência do seu legado, promovendo uma sociedade mais justa, equitativa, igualitária e integralmente respeitadora dos direitos humanos, com a convicção de que as suas ideias interpelam, a cada momento, o nosso presente e inspiram o nosso futuro.

53 Condorcet, Bosquejo de um cuadro histórico de los progressos del espírito bumano, cit., «Décima época», pp. 157 a 184. 